\title{
Washing and Dyeing Wastewater Treatment by Combined Nano Flocculation and Photocatalysis Processes
}

\author{
Yamei Dong1, Ting Wang1, Xiaojia Wan", ${ }^{1,2}$ Dannong He $\mathrm{H}^{1,2}$ \\ ${ }^{1}$ National Engineering Research Center for Nanotechnology, Shanghai, China \\ ${ }^{2}$ School of Materials Science and Engineering, Shanghai Jiao Tong University, Shanghai, China \\ Email: ymdong515@163.com, hdn nercn@163.com
}

Received February 2015

\begin{abstract}
The research investigated the performance of combined process (flocculation pretreatment-photo catalysis). The characteristics of nano flocculation and photocataly were evaluated by simulated dye and surfactant wastewater. In the coagulation and settling period, decolorization rate of five dyes wastewater by nano flocculant was higher than $95 \%$. In the photocatalytic period, degradation of twelve sodium dodecyl benzene sulfonate reached $33 \%$. Washing and dyeing wastewater treated by combined process conformed to the "textile dyeing and finishing industry back to the water quality standard" (FZ/T 01107-2011). The results showed that the combined process was highly advanced treatment for washing and dying wastewater.
\end{abstract}

\section{Keywords}

\section{Washing and Dyeing Wastewater, Nano Flocculation, Nano Photocatalysie}

\section{Introduction}

Washing and dyeing industry is a new industry developed in recent years. The washing and dyeing wastewater is refers to the waste water produced in washing, washing and dyeing industry, dyeing, ironing process of darning etc. It is difficult to concentrate processing, are generally discharged into the city sewage pipe network or direct discharge. Washing and dyeing wastewater containing surfactant, dyes and other non dissolved impurities and other pollutants. If incorporated into the municipal sewage pipe network into the sewage treatment plant will form a bubble mountain, interference of waste water treatment, reduction of biological filter bed and activity of activated sludge, if directly discharged it into the natural water would pollute the water, causing serious environmental problems. Therefore, the washing and dyeing wastewater advanced treatment and reuse treatment is very important.

How to effectively remove pollutant from washing and dying wastewater is a hot topic in reclaimed water reuse field. There were many researches on dye wastewater treatment [1] [2]. The main treatment process includes direct filtration process; countercurrent washing method, membrane bioreactor used back washing and 
dyeing wastewater [3] [4]. The advantage of biological method is low cost, but the treatment effect is easily influenced by inlet water quality fluctuation [5]. The activated carbon adsorption treatment cost is high, and the regeneration is difficult [6]. Membrane separation technology requires large one-time investment and high cost of running [7]. At present, most washing and dyeing industry wastewater are directly discharged into the city pipe network by the end of treatment. This year, with the development of nanotechnology, nano materials by nano flocculant optimization has more excellent settleability. Nano Photocatalysis technology had attracted for contaminated water treatment has gained wide attention in the past years, because high stability, low cost and nontoxicity and no secondary contamination. Especially using other elements doped titanium dioxide broadens the spectrum absorption range. Doped nano photocatalyst can removal of organic pollutants in water in the sun [8].

According to the characteristics of washing and dyeing industry wastewater, this paper adopts nano flocculation and visible light catalytic oxidation coupling technique. Development and application of high efficiency adsorption flocculant can greatly reduce water turbidity and color, improve the light transmittance, at the same time, by titania modified titanium oxide catalyst can broaden the scope of visible light absorption, the realization of the photocatalytic degradation of dyeing wastewater under visible light in the organic pollutants, and reach the level of reuse. This research suggests a combined process which is composed of nano coagulation and photocatalyst system. The purpose of this study was provides a reference for the engineering application of washing and dyeing wastewater reuse.

\section{Material and Methods}

\subsection{Materials}

The following chemicals were work: twelve water potassium aluminum sulfate, ammonia, sodium hydroxide, potassium dichromate, hydrochloric acid, cerium nitrate, four of butyl titanate (TBT), ammonium metavanadate, thiourea, oxalic acid, ethanol (above all were analytically pure and purchased from Sinopharm Chemical Reagent Co., ltd.), deionized water, powdered activated carbon (300 - 400 mesh, Haiyu activated carbon factory).

The washing and dyeing wastewater used in the experimental was from a dyeing factory in Zhejiang Province. Physicochemical properties of the wastewater were as followed: $\mathrm{pH} 6.0-8.0$, COD $400-600 \mathrm{mg} / \mathrm{L}$, chroma 600 -800 .

\subsection{Synthesis and Application of Nano Flocculant}

By sol-gel method, with four ethyl orthosilicate as precursor, ethanol and water in the mixed solution of water bath heating to $700^{\circ} \mathrm{C}$, stirring $90 \mathrm{~min}$, adding proper amount of catalyst, continue stirring 60 min after the formation of white gel, $\mathrm{pH}$ control in $5-6$, after the completion of the reaction, the aging $24 \mathrm{~h}$, after drying and mixed according to the proportion of kaolin ball milling, and then in the annealed at $700^{\circ} \mathrm{C} 60 \mathrm{~min}$ after dissolving with acid activated 120 min, 300 - 400 mesh of powdered activated carbon and adding a certain proportion, using sodium carbonate as regulator, adjust the polymerization with $\mathrm{pH}$ as $6-7$, adding ammonia to the solution of $\mathrm{pH}$ is $9-11$, the water bath curing time is $240 \mathrm{~min}$, curing temperature is $600^{\circ} \mathrm{C}$, the solution is layered later, with the deionized water to neutral, repeated washing capacity, before using the oscillating uniform.

The nano flocculant was used in simulated wastewater of different dye solution $(0.03 \%)$, determination of chromaticity before and after flocculation, and calculate the decolorization rate. Then the applications of nano flocculant to the actual washing and dyeing wastewater, chromaticity and COD were measured before and after flocculation, and calculate the decolorization rate and COD removal rate.

\subsection{Synthesis and Application of Nano Photocatalysie}

With ammonium metavanadate and four of butyl titanate as precursor, with citric acid as inhibitor, in a mixture of ethanol and aqueous solution, the temperature of $400^{\circ} \mathrm{C}$ water bath heating stirring 30 min, aging 7 days after ball milling, drying calcination 4 hours at $400^{\circ} \mathrm{C}$, vanadium doped titanium dioxide photocatalyst is obtained. Doping ratio of ammonium metavanadate in $\mathrm{TiO}_{2}$ was $0 \%, 1 \%, 2 \%, 3 \%, 4 \%$ and $5 \%$. Configure the concentration of $10 \mathrm{mg} / \mathrm{L}$ twelve sodium dodecyl benzene sulfonate (SDBS) solution, titanium dioxide photocatalysts doped with vanadium $400^{\circ} \mathrm{C}$ prepared by the concentration of $1 \mathrm{~g} / \mathrm{L}$ added to the SDBS solution, stirring $1 \mathrm{~h}$ and adsorption equilibrium, ultraviolet degradation of $2 \mathrm{~h}$, to determine the concentration of SDBS solution in dif- 
ferent time, and calculate the degradation rate of SDBS.

\subsection{Analytical Methods}

Chemical oxygen demand as permanganate demand (COD) and suspended solids (SS) were determined according to the methods described in the standard methods for the examination of water and wastewater [9]. Chromaticity and turbidity were measured using a Hach model DR890 photometer. The concentrations of dyes and SDBS solution were determined by using a Lambda 950 (PerkinElmer) spectrometer.

\subsection{Experimental Setup}

The continuous combined process for washing and dyeing wastewater consists of coagulation and settling reactor and photocatalytic system. A flow diagram of the continuous washing and dyeing wastewater treatment system used in this study is shown in Figure 1. Flocculation pretreatment was carried out in an up-flow inner circulation coagulation and settling reactor. The washing and dyeing wastewater with a certain velocity into the flocculation sedimentation tank, while adding nano flocculant, the waste water and the nano flocculant mixed rapidly within the reactor settlement, removing most of the chroma and COD, and then the sludge discharged from the bottom. The supernatant from the upper overflow weir inflow photocatalytic reactor, after photocatalytic degradation in the sunlight further the removal of COD, to achieve the reuse standard.

\section{Results and Discussion}

\subsection{Decolorization of Simulated Dye Wastewater by Nano Flocculant}

The nano flocculant was used in decolorizing treatment of simulated dye wastewater. The results of treatment and decolorization were shown in Figure 2. As we can see from Figure 2, decolorization of dye wastewater by

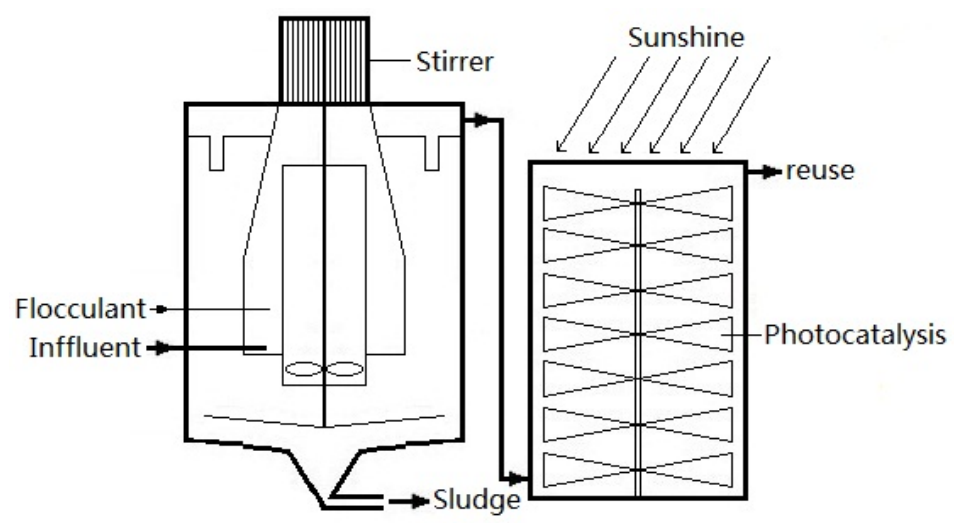

Figure 1. Flow diagram of combined process for washing and dyeing wastewater treatment.

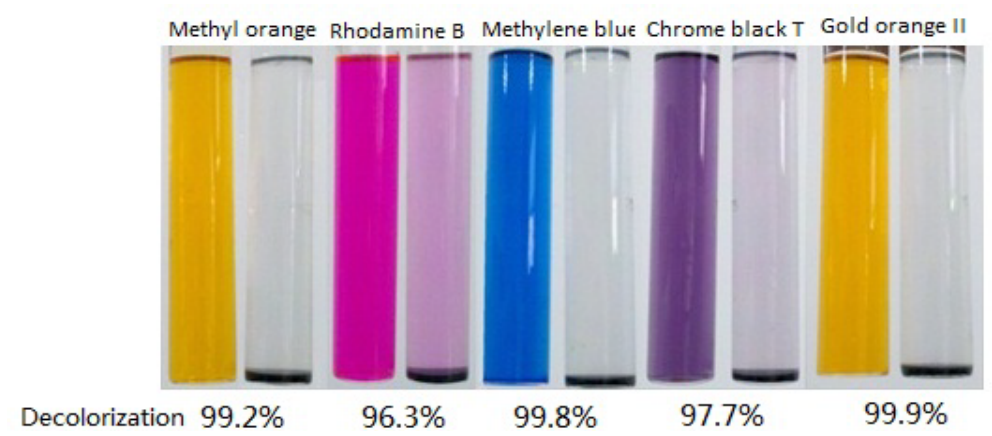

Figure 2. Effect of treatment of simulated dye wastewater with nano flocculant. 
nano flocculant was higher than $95 \%$. It confirmed that the adsorption and sedimentation of dye by nano flocculant was perfect. These results can be further applied in the decolorizing treatment practice of washing and dyeing wastewater.

\subsection{Decolorization and COD Removal Rate of Washing and Dying Wastewater by Nano Flocculant}

The nano flocculant was used in decolorizing and COD removal treatment of washing and dying wastewater. The results were shown in Figure 3.

After deposition for $30 \mathrm{~min}$, washing and dyeing wastewater decolorization rate and COD removal rate of washing and dyeing wastewater reached $95 \%$ and $80 \%$ respectively. Supernatant was almost colorless, and COD was about $60-80 \mathrm{mg} / \mathrm{L}$.

\subsection{SDBS Removal Rate of Washing and Dying Wastewater by Nano Photocatalysie}

As shown in Figure 4, doping transition metal vanadium, titanium dioxide visible light absorption range can be increased to $570 \mathrm{~nm}$. Titanium dioxide visible light absorption range increases with vanadium doping quantity increased, the increase amplitude decreases with the increase of the amount of doping.

Vanadium doped titanium dioxide photocatalyst although can make visible light absorption range increased, but the photocatalytic degradation rate of SDBS did not increase (Figure 5). When the doping amount was 1\%, the strongest inhibition was showed on the photocatalytic effect. When the doping concentration of $3 \%-5 \%$, the photocatalytic degradation rate increases with the increase of SDBS doping amount increase. When the doping amount was $5 \% 2 \mathrm{~h}$, the photocatalytic degradation of SDBS was the highest, reached $33 \%$.

\subsection{Combined Nano Flocculation and Photocatalysis Processes}

According to the experimental results, using combined treatment process in Figure 1 for continuous treatment of the actual dyeing wastewater. In the phase of flocculation precipitation, the quantity of added nano flocculant is $0.5 \%-1 \%(\mathrm{~V} / \mathrm{V})$, hydraulic retention time of $30 \mathrm{~min}$. Photocatalytic stage, selection of vanadium doped amount of visible light catalyst 5\%, water adding amount of $1 \mathrm{~g} / \mathrm{L}$ hydraulic retention time was $2 \mathrm{~h}$. The water qualities were measured before and after treatment, and contrasted with textile dyeing and finishing industry back to the water quality standard contrast. The results are shown in Table $\mathbf{1}$.

All the water quality indexes by using the washing and dyeing wastewater combined nano flocculation and photocatalysis processes treated have reached a "textile dyeing and finishing industry back to the water quality

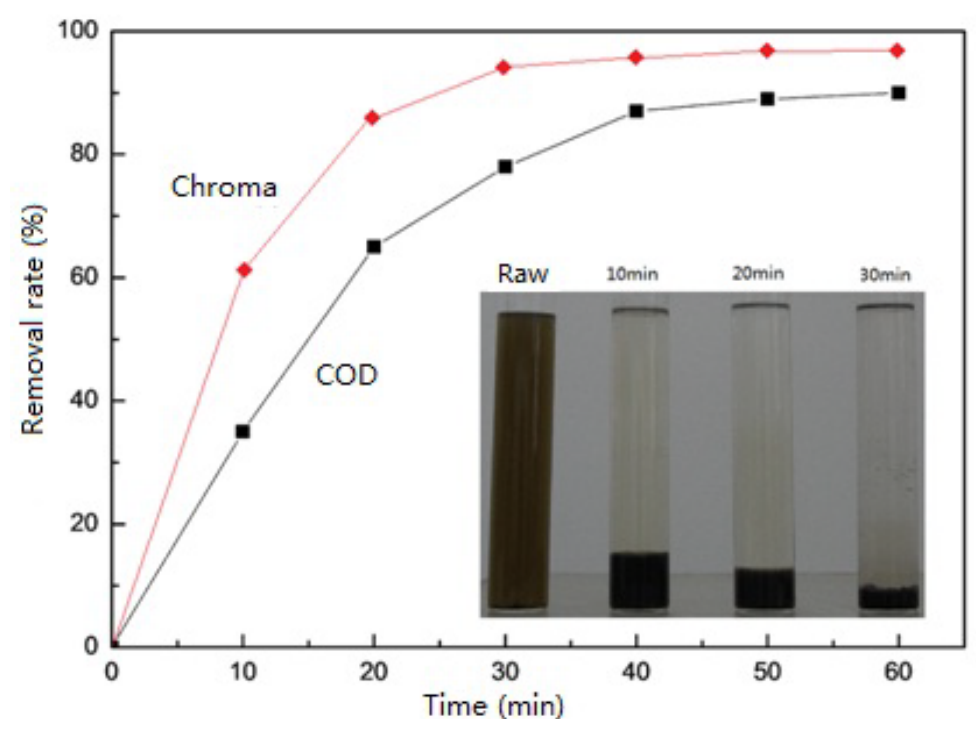

Figure 3. Effect of treatment of washing and dying wastewater with nano flocculant. 


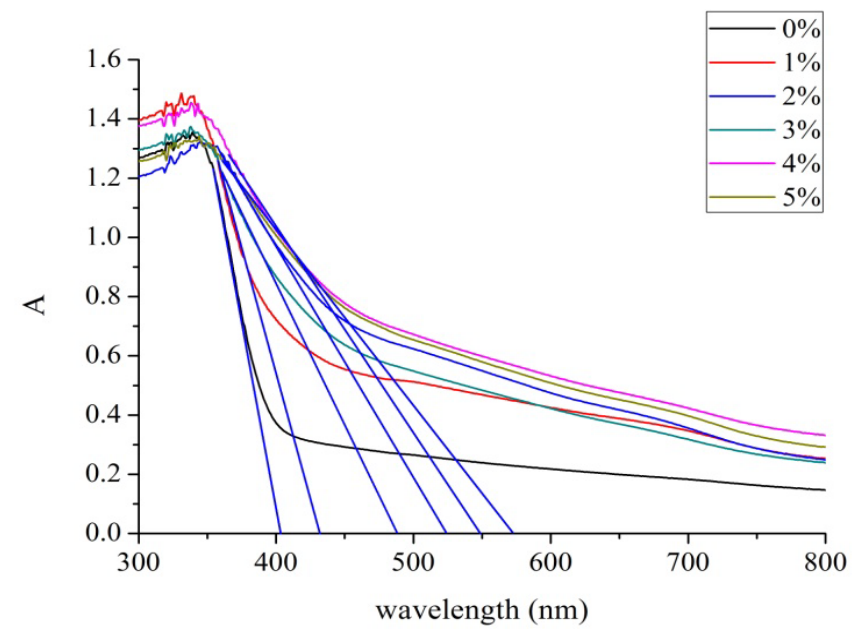

Figure 4. Absorption wavelength of vanadium doped titanium dioxide photocatalyst.

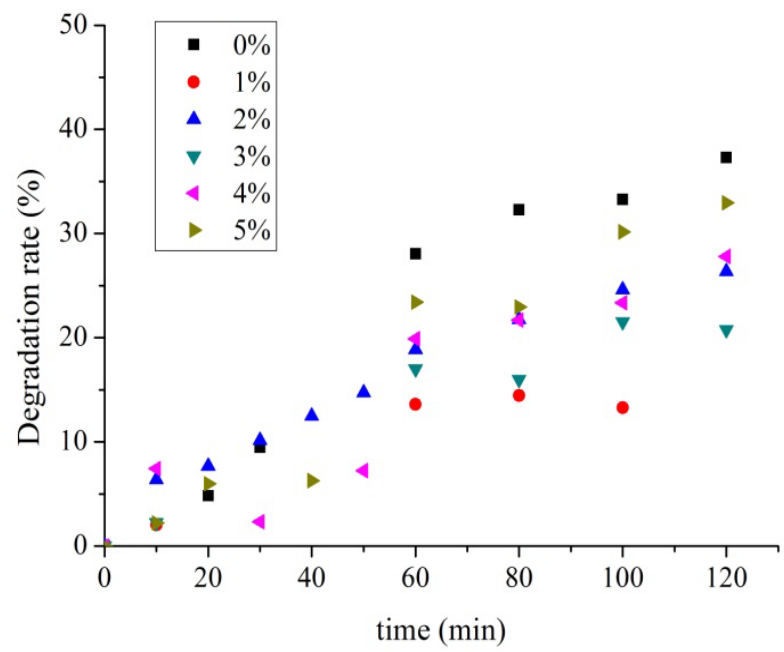

Figure 5. Degradation of SDBS by doped vanadium titanium dioxide photocatalyst.

Table 1. Water quality before and after the treatment and reuse of standards.

\begin{tabular}{cccc}
\hline Parameters & Influent & Effluent & Standards \\
\hline $\mathrm{pH}$ & $6.0-8.0$ & 7.17 & $6.0-9.0$ \\
$\mathrm{COD}(\mathrm{mg} / \mathrm{L})$ & $400-600$ & $<30$ & $\leq 50$ \\
$\mathrm{SS}$ & $300-500$ & 12 & $\leq 30$ \\
Chroma & $600-800$ & 6 & $\leq 25$ \\
\hline
\end{tabular}

standard" (FZ/T 01107-2011), which can realize the washing and dyeing wastewater recycling, and achieve the goal of energy saving and emission reduction.

\section{Conclusion}

In this study of nano flocculation pretreatment technology was combined with photocatalysis technology for 
washing and dyeing wastewater. The use of nano flocculation pretreatment technique was to remove most of the pollutants, such as particles, turbidity, bacteria, etc. The use of nano photocatalyt was to remove the soluble contaminants of washing and dyeing wastewater. From these results, compared with traditional wastewater treatment, the combined process (flocculation pretreatment-photocatalysis) was a great potential technology for washing and dyeing wastewater advanced treatment.

\section{Acknowledgements}

The work was supported by the International Science \& Technology Cooperation Program of China (KY201302007), the Shanghai Municipal Natural Foundation (No. 13ZR1429300), the Basic Research Program of Shanghai Science and Technology Committee (No. 13NM1401600), the Shanghai Committee of Science and Technology (No. 12nm0504800).

\section{References}

[1] Rajkumar, D. and Kim, J.G. (2006) Oxidation of Various Reactive Dyes with in Situ Electro-Generated Active Chlorine for Textile Dyeing Industry Wastewater Treatment. Journal of Hazardous Materials, 136, 203-212. http://dx.doi.org/10.1016/j.jhazmat.2005.11.096

[2] Liu, C.H., Wu, J.S., Chiu, H.C., Suen, S.Y. and Chu, K.H. (2007) Removal of Anionic Reactive Dyes from Water Using Anion Exchange Membranes as Adsorbers. Water Research, 41, 1491-1500. http://dx.doi.org/10.1016/j.watres.2007.01.023

[3] Yang, Q., Wang, J., Wang, H., Chen, X., Ren, S., Li, X., Xu, Y., Zhang, H. and Li, X. (2012) Evolution of the Microbial Community in a Full-Scale Printing and Dyeing Wastewater Treatment System. Bioresource Technology, 117, 155-163. http://dx.doi.org/10.1016/i.biortech.2012.04.059

[4] Wu, H. and Wang, S. (2012) Impacts of Operating Parameters on Oxidation-Reduction Potential and Pretreatment Efficacy in the Pretreatment of Printing and Dyeing Wastewater by Fenton Process. Journal of Hazardous Materials, 243, 86-94. http://dx.doi.org/10.1016/j.jhazmat.2012.10.030

[5] Senthilkumar, M., Gnanapragasam, G., Arutchelvan, V. and Nagarajan, S. (2010) Treatment of Textile Dyeing Wastewater Using Two-Phase Pilot Plant UASB Reactor with Sago Wastewater as Co-Substrate. Chemical Engineering Journal, 166, 10-14. http://dx.doi.org/10.1016/j.cej.2010.07.057

[6] Kadirvelu, K., Palanival, M., Kalpana, R. and Rajeswari, S. (2000) Activated Carbon from an Agricultural by-Product, for the Treatment of Dyeing Industry Wastewater. Bioresource Technology, 74, 263-265. http://dx.doi.org/10.1016/S0960-8524(00)00013-4

[7] Feng, F., Xu, Z., Li, X., You, W. and Zhen, Y. (2010) Advanced Treatment of Dyeing Wastewater towards Reuse by the Combined Fenton Oxidation and Membrane Bioreactor Process. Journal of Environmental Sciences, 22, 1657-1665. http://dx.doi.org/10.1016/S1001-0742(09)60303-X

[8] Soares, P.A., Silva, T.F.C.V., Manenti, D.R., Souza, S.M.A.G.U., Boaventura, R.A.R. and Vilar, V.J.P. (2013) Insights into Real Cotton-Textile Dyeing Wastewater Treatment Using Solar Advanced Oxidation Processes. Environmental Science and Pollution Research, 21, 932-945. http://dx.doi.org/10.1007/s11356-013-1934-0

[9] APHA (American Public Health Association), AWWA (American Water Works Association) and WEF (Water Environment Federation) (1999) Standard Methods for the Examination of Water and Wastewater. 20th Edition, Washington DC. 